\title{
Enhanced propagation of fish nodaviruses in BF-2 cells persistently infected with snakehead retrovirus (SnRV)
}

\author{
Toyohiko Nishizawa*, Yuki Kokawa, Takako Wakayama, Shinichi Kinoshita, \\ Mamoru Yoshimizu
}

Faculty of Fisheries Sciences, Hokkaido University, Hakodate, 041-8611 Japan

\begin{abstract}
Fish nodaviruses are causative agents of viral nervous necrosis causing high mortality in cultured marine fishes around the world. The first successful isolation of fish nodavirus was made with SSN-1 cells, which are persistently infected with snakehead retrovirus (SnRV). In the present study, a BF-2 cell line persistently infected with SnRV (PI-BF-2) was established to evaluate the influence of SnRV on the production of fish nodavirus. The PI-BF-2 cells were slightly more slender than BF-2 cells, but no difference was observed in propagation rate between both cell lines. No difference was observed in production of SnRV between PI-BF-2 and SSN-1 cell lines. Although both PI-BF-2 and BF-2 cell lines showed no cytopathic effect (CPE) after inoculation of striped jack nervous necrosis virus (SJNNV) and redspotted grouper nervous necrosis virus (RGNNV), these fish nodaviruses could be amplified in BF-2 cells, and moreover, production of fish nodaviruses in the PI-BF-2 cell line was more than 40 times higher than in BF-2 cells. Thus, it was concluded that BF-2 cell permissiveness to fish nodaviruses was enhanced by persistent infection with SnRV. Furthermore, homologous cDNA to genomic RNA of SJNNV was detected from both PI-BF-2 and SSN-1 cell lines persistently infected with SnRV. The amount of nodavirus cDNA in SJNNV-inoculated PI-BF-2 cells was clearly lower than that in SJNNV-inoculated SSN-1 cells.
\end{abstract}

KEY WORDS: Persistent infection $\cdot$ Fish nodavirus $\cdot \mathrm{SJNNV} \cdot \mathrm{RGNNV} \cdot$ Retrovirus $\cdot \mathrm{SnRV}$

\section{INTRODUCTION}

Fish nodaviruses, members of the genus Betanodavirus in the family Nodaviridae, are causative agents of viral nervous necrosis (VNN) or viral encephalopathy and retinopathy (VER) causing high mortality in $>20$ species of cultured marine fishes around the world (Muroga et al. 1998, Muroga 2001, Munday et al. 2002, Schneemann et al. 2005). These viruses are nonenveloped and spherical in shape, have a diameter of 25 to $30 \mathrm{~nm}$, consist of a single coat protein with a molecular mass of $42 \mathrm{kDa}$ and 2 molecules of positive sense single-stranded RNA (ssRNA) without poly(A) tails at 3' ends; RNA1 (3.1 kb) encodes an RNA-dependent RNA polymerase while RNA2 (1.4 kb) encodes the coat protein (Mori et al. 1992, Comps et al. 1994,
Nagai \& Nishizawa 1999, Iwamoto et al. 2001, Tan et al. 2001, Schneemann et al. 2005). Based on nucleotide sequences, fish nodaviruses are classified into 4 genotypes: striped jacked nervous necrosis virus (SJNNV), tiger puffer NNV (TPNNV), barfin flounder NNV (BFNNV) and redspotted grouper NNV (RGNNV) (Nishizawa et al. 1995, 1997). New nodavirus isolates from turbot Scophthalmus maximus have been proposed as a fifth genotype (Johansen et al. 2004).

Several attempts have been made to culture fish nodaviruses in available fish cell lines, such as RTG-2, CHSE-214, FHM, EPC and BF-2, but generally without success (Breuil et al. 1991, Mori et al. 1991, Munday et al. 1992, Nguyen et al. 1994, Grotmol et al. 1995). Due to this inability to isolate the virus in cell culture, alternative detection methods, such as RT-PCR, have been 
developed (Nishizawa et al. 1994). The first successful isolation of a nodavirus, Dicentrarchus labrax encephalitis virus (DIEV, the RGNNV type), was made from sea bass D. labrax using the SSN-1 cell line derived from striped snakehead Ophicephalus striatus (Frerichs et al. 1996). The SSN-1 cell line has been shown to be highly permissive to other fish nodaviruses (Iwamoto et al. 1999). Subsequently, several new cell lines with susceptibility to fish nodaviruses have been reported, such as SBL and SB cell lines derived from sea bass, GF-1 and GS cell lines from orange spotted grouper Epinephelus coioides, GB, GF and GL cell lines from yellow grouper E. awoara, and ASF from gilthead seabream Sparus auratus (Delsert et al. 1997, Chew-Lim et al. 1998, Chi et al. 1999, Lai et al. 2001, Bandín et al. 2006, Qin et al. 2006).

The SSN-1 cell line is persistently infected with snakehead retrovirus (SnRV), a C-type retrovirus that is 85 to $95 \mathrm{~nm}$ in diameter and has high $\mathrm{Mn}^{2+}$-dependent reverse transcriptase activity (Frerichs et al. 1991). SnRV was originally identified as a spontaneously productive infection in the SSN-1 cell line, and distinguishable from all known retrovirus groups by the presence of an arginine transfer RNA (tRNA) primer-binding site (Frerichs et al. 1991, Hart et al. 1996). Iwamoto et al. (2000) produced several cloned cell lines from the SSN-1 cell line, but SnRV was detectable from all of the cloned cell lines permissive for nodavirus infection. Thus, it was suggested that persistent infection with SnRV had an important role in permissiveness of SSN-1 cells for fish nodaviruses (Iwamoto et al. 2000). However, Lee et al. (2002) induced a persistent SnRV-infection in the GF-1 cell line (SGF-1) to compare the productivity of grouper NNV (GNNV), a fish nodavirus, and concluded that the presence of SnRV in SGF cells did not increase or decrease the production of GNNV. Involvement in the life cycle of fish nodavirus by SnRV is still not clear. Thus, in the present study, we persistently infected a BF-2 cell line with SnRV (PI-BF-2) to evaluate the influence of SnRV on the production of fish nodaviruses.

\section{MATERIALS AND METHODS}

Viruses. SJ93Nag (SJNNV genotype) isolated from VNN-affected striped jack Pseudocaranx dentex at Nagasaki Prefecture in 1993 (Nishizawa et al. 1997), SgNag05 (RGNNV genotype) from sevenband grouper Epinephelus septemfasciatus at Nagasaki Prefecture in 2005 (Y. Kokawa et al. unpubl. data) and SnRV obtained from culture fluid of SSN-1 cell lines were used in the present study. SJNNV and RGNNV were cultured at $25^{\circ} \mathrm{C}$ in SSN-1 cells, while SnRV was cul- tured at $25^{\circ} \mathrm{C}$ in BF-2 cells. Both SSN-1 and BF-2 cell lines were maintained using Leibovitz L-15 medium (Gibco) with $10 \%\left(\mathrm{v} / \mathrm{v}\right.$ ) fetal bovine serum, $150 \mathrm{IU} \mathrm{ml}^{-1}$ penicillin $\mathrm{G}$ and $100 \mu \mathrm{g} \mathrm{ml}^{-1}$ streptomycin. SJNNV and RGNNV were treated with $1 \%$ Triton $\mathrm{X}-100$ at $20^{\circ} \mathrm{C}$ for 30 min to inactivate SnRV produced concurrently with the nodavirus by the SSN-1 cells (TrX-SJNNV and TrX-RGNNV, respectively). The TrX-nodaviruses were pelleted $\left(150000 \times g, 1 \mathrm{~h}, 4^{\circ} \mathrm{C}\right)$, and resuspended in $\mathrm{L}-15$ and stored at $-80^{\circ} \mathrm{C}$ until use.

PI-BF-2 cells with SnRV. BF-2 cells were inoculated with SnRV at a multiplicity of infection (MOI) of approximately 2.5 and incubated at $25^{\circ} \mathrm{C}$, and the surviving BF-2 cells from SnRV infection were harvested. After being subcultured several times, the surviving BF-2 cells were analyzed by PCR with primers targeting the SnRV pol gene, ML1 and GPOL2, as described below ('RT-PCR amplification'). The BF-2 cells, confirmed SnRV proviral DNA positive, were used in experiments as a persistently SnRV-infected BF-2 cell line (PI-BF-2). The PI-BF-2 cell line was maintained under the same conditions as the BF-2 cell line, and PIBF-2 cells with around 50 passages were used in experiments.

Viral productivity of cell lines. In experiments for SnRV productivity, BF-2, PI-BF-2 and SSN-1 cells were seeded into $25 \mathrm{~cm}^{2}$ culture flasks at approximately $2.5 \times 10^{6}$ cells flask $^{-1}$ and cultured at $25^{\circ} \mathrm{C}$ for $24 \mathrm{~h}$. The adherent cells were washed 3 times with fresh medium and cultured for an additional 2 wk with an aliquot of culture fluid collected every 2 or $3 \mathrm{~d}$ for titration of SnRV infectivity. In experiments for fish nodaviral productivity, BF-2 and PI-BF-2 cells were cultured in the same manner as described above. After washing with fresh medium, the cells were inoculated with either TrX-SJNNV or TrX-RGNNV at an MOI of 0.001, and cultured for an additional 2 wk with an aliquot of the culture fluid collected every 2 or $3 \mathrm{~d}$ for titration of nodavirus infectivity. Titration of viral infectivity was performed using 96-well microplates, seeded with SSN-1 cells for SJNNV and RGNNV, or with BF-2 cells for SnRV. After culture at $25^{\circ} \mathrm{C}$ for $14 \mathrm{~d}$, cytopathic effect (CPE) was evaluated to determine the $50 \%$ tissue culture infectious dose $\left(\mathrm{TCID}_{50}\right)$.

RT-PCR amplification. Viral RNA was extracted using an RNA extraction kit (Isogen, Nippon Gene) according to the manufacturer's instructions. Extracted RNA was heat-denatured at $95^{\circ} \mathrm{C}$ for $5 \mathrm{~min}$ and then incubated at $42^{\circ} \mathrm{C}$ for $30 \mathrm{~min}$ in $10 \mu \mathrm{l}$ of PCR buffer (10 mM Tris- $\mathrm{HCl}$ [pH 8.3], $50 \mathrm{mM} \mathrm{KCl)} \mathrm{containing}$ $100 \mathrm{U}$ of Moloney murine leukemia virus reverse transcriptase (Takara), $1 \mu \mathrm{M}$ reverse primer, $1 \mathrm{mM}$ deoxynucleoside triphosphates (dNTP) and $5 \mathrm{mM} \mathrm{MgCl}_{2}$. After incubation at $99^{\circ} \mathrm{C}$ for $10 \mathrm{~min}$, the targeted cDNA was amplified in $50 \mu \mathrm{l}$ of PCR buffer containing $0.2 \mu \mathrm{M}$ 
of each primer, $1.25 \mathrm{U}$ of EX-Taq DNA polymerase (Takara), $0.2 \mathrm{mM}$ dNTP and $2 \mathrm{mM} \mathrm{MgCl}_{2}$ with a thermal cycler programmed for 1 cycle at $72^{\circ} \mathrm{C}$ for $10 \mathrm{~min}$; $95^{\circ} \mathrm{C}$ for $2 \mathrm{~min} ; 30$ cycles, each consisting of $95^{\circ} \mathrm{C}$ for $50 \mathrm{~s}, 52^{\circ} \mathrm{C}$ (F2-R3 primer set) or $60^{\circ} \mathrm{C}$ (ML1-GPOL2 set) for $50 \mathrm{~s}$, and $72^{\circ} \mathrm{C}$ for $50 \mathrm{~s}$; and a final hold step at $72^{\circ} \mathrm{C}$ for $5 \mathrm{~min}$. Two primer sets were used. The first primer set, F2 (5'-CGT GTC AGT CAT GTG TCG CT-3') and R3 (5'-CGA GTC AAC ACG GGT GAA GA-3'), targets the $\mathrm{T} 4$ region to produce a 427 -base amplicon of the nodavirus genome RNA2 (Nishizawa et al. 1994). The second primer set consists of ML1 (5'-TGG TAC CCA TGG ATA CAG GTA CCT CA-3') and GPOL2 (5'-TGT CAG ACA TGG CCT GTA CTT TAG CAG C-3'), targeting a 730-base region of the SnRV reverse transcriptase (pol) gene (Hart et al. 1996). The amplified products were analyzed by $1.5 \%$ agarose-TAE (40 mM Tris-acetate [pH 8.0], 1 mM EDTA) gel electrophoresis and visualized under UV irradiation after being stained with ethidium bromide.

PCR amplification. BF-2, PI-BF-2 and SSN-1 cells were inoculated with TrX-SJNNV for detection of proviral DNA of SnRV and genomic cDNA of fish nodavirus. After culturing at $25^{\circ} \mathrm{C}$ for $10 \mathrm{~d}$, each cell type and their culture fluids were collected for extraction of total nucleic acids as described by Nishizawa et al. (1994, 1995), and were subjected to PCR amplification. Briefly, $1 / 10$ volume of Proteinase K (10 $\mathrm{mg} \mathrm{ml}^{-1}$ ) and Tween 20 (5\%) were added to the cell suspension and culture fluid and incubated at $37^{\circ} \mathrm{C}$ for $15 \mathrm{~min}$. Total nucleic acids were extracted with TE-saturated phenol (twice) and chloroform-isoamyl alcohol (24:1) (once), and were subjected to PCR amplification with the primer set F2-R3 or ML1-GPOL2. Procedures for PCR amplification and agarose-TAE gel electrophoresis analysis were as described above.

\section{RESULTS}

SSN-1 cells are highly susceptible to fish nodaviruses, but are also persistently infected with the Ctype retrovirus SnRV, which can be induced to a cytolytic infection in cultures of BF-2 cell line (Frerichs et al. 1991, 1996). Although CPE with globular-shaped cells is generally observed in BF-2 cells after SnRV inoculation, we recently found that SnRV inoculation at a $\mathrm{MOI} \geq 1.0$ induced almost no $\mathrm{CPE}$ in BF-2 cells (data not shown). Thus in the present study, BF-2 cells were inoculated with SnRV at a MOI of 2.5, and the surviving BF-2 cells were subcultured for induction of PI-BF-2 cells. The newly established PI-BF-2 and normal BF-2 cells were stained with May-Grünwald Giemsa at $2 \mathrm{~d}$ postsubculture for morphological evaluation by light microscopy (Fig. 1). The PI-BF-2 cells seemed to be slightly smaller and more slender than normal BF-2 cells (Fig. 1), but no difference was observed in the propagation rate between both cell

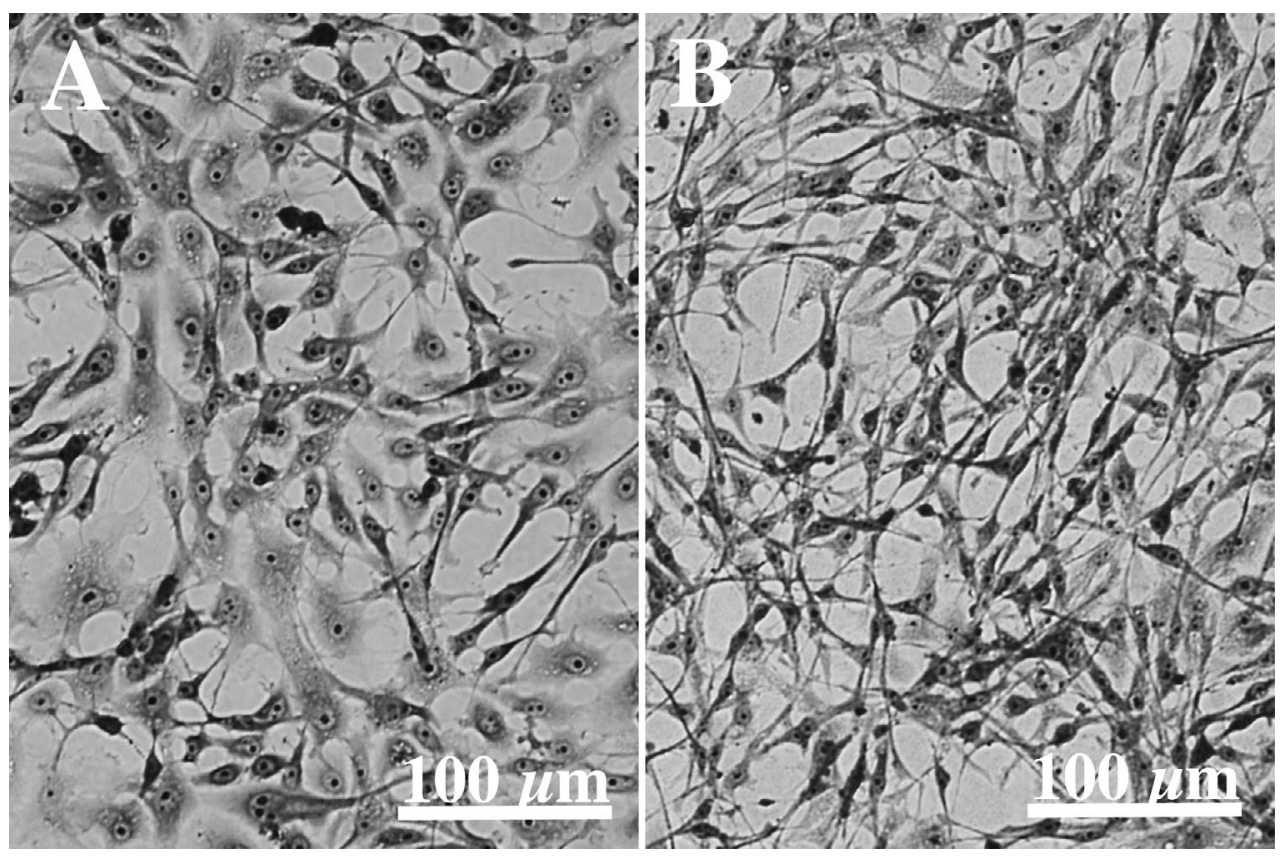

Fig. 1. Photomicrographs of (A) original BF-2 cells and (B) BF-2 cells persistently infected with snakehead retrovirus (SnRV) (PI-BF-2 cells), both stained with May-Grünwald Giemsa 2 d post-subculture 


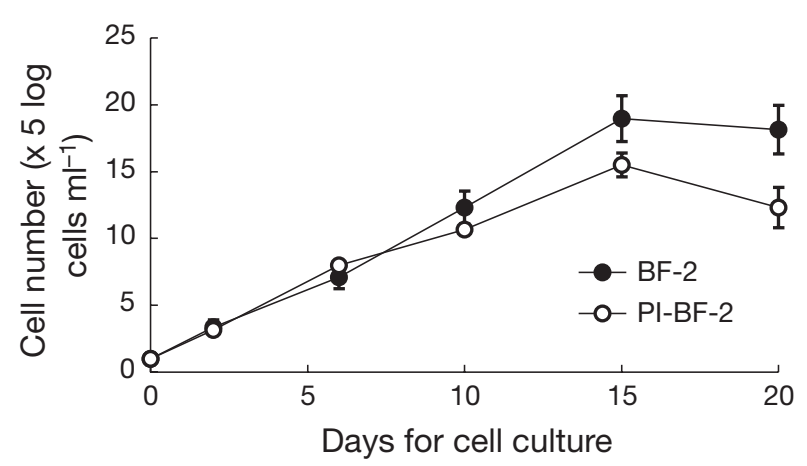

Fig. 2. Propagation curves of normal BF-2 and newly established PI-BF-2 cell lines cultured at $25^{\circ} \mathrm{C}$

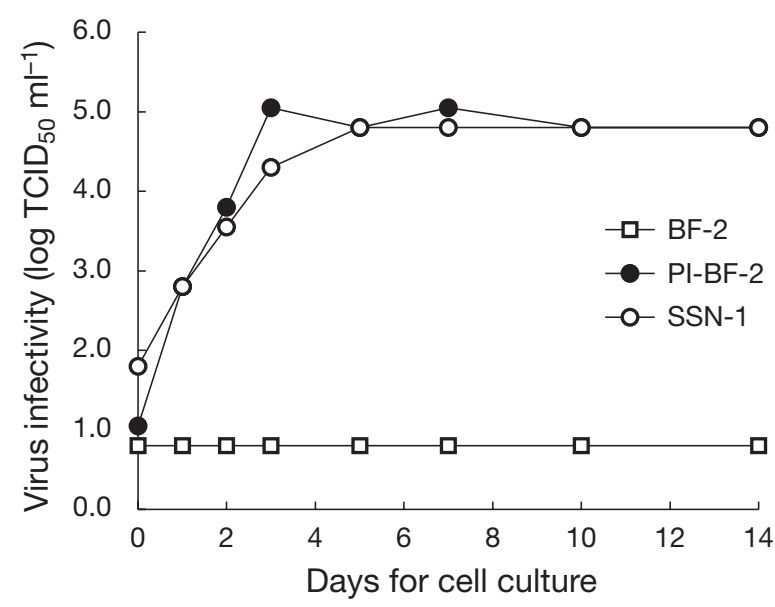

Fig. 3. Production of snakehead retrovirus (SnRV) by PI-BF-2, BF-2 and SSN-1 cell lines. Change of infectivity titer of SnRV in culture fluid of these cell lines was monitored. In the present system, the detection limit of viral titer was $>0.8$ TCID $_{50}$ $\mathrm{ml}^{-1}$; thus, virus titer under the detection limit shown as $0.8 \mathrm{TCID}_{50} \mathrm{ml}^{-1}$

lines (Fig. 2). Following inoculation with SnRV, CPE was induced in BF-2 cells, but not in the PI-BF-2 cells at any MOI (data not shown).

For comparison of production of SnRV in PI-BF-2, BF-2 and SSN-1 cell lines (Fig. 3), the titer of SnRV in the culture fluid of both PI-BF-2 and SSN-1 cells was $2.8 \log \mathrm{TCID}_{50} \mathrm{ml}^{-1}$ on the first day of culture, and reached $4.8 \log \mathrm{TCID}_{50} \mathrm{ml}^{-1}$ by the fifth day of culture. No difference was observed in SnRV production between PI-BF-2 and SSN-1 cells. The SnRV productivity by PI-BF-2 cells was calculated to be approximately 0.03 TCID $_{50}$ cell $^{-1} \mathrm{~d}^{-1}$, which was 100 times lower than that produced by cytolytically SnRVinfected BF-2 cells. Although the PI-BF-2 cell line used in the present experiments was subcultured more than 50 times, SnRV was stably produced in the culture fluid of the PI-BF-2 cell line. No titer of SnRV was detected in normal BF-2 cells.
To confirm the life cycle of SnRV in PI-BF-2 cells, extracted nucleic acids from cultured BF-2, PI-BF2 and SSN-1 cells were subjected to RT-PCR and PCR with the primer set ML1-GPOL2 targeting the SnRV pol gene (Fig. 4). The RT-PCR products amplified from the RNA of cultured PI-BF-2 and SSN-1 cells, as well as the culture fluids, were $730 \mathrm{bp}$ in size, corresponding to the target region of the PCR primers. RT-PCR products were amplified from neither BF-2 cells nor the culture fluids from the BF-2 cultures. PCR products with $730 \mathrm{bp}$ were amplified from nucleic acids of PI-BF-2 and SSN-1 cells, but not from those of BF-2 cells. Furthermore, no PCR product was amplified from culture fluids from any of the 3 cell lines. These results suggested that proviral DNA of SnRV was reversibly integrated into the genomic DNA of PI-BF-2 cells as a spontaneously productive infection.

For comparison of permissiveness of BF-2 and PI-BF2 cells to nodaviruses, TrX-SJNNV and TrX-RGNNV were inoculated and cultured to monitor the viral infectivity titers in the culture fluid (Fig. 5). By inoculation with TrX-SJNNV, SJNNV titer in culture fluid of the BF-2 cells reached $3.05 \log \mathrm{TCID}_{50} \mathrm{ml}^{-1}$, while the maximum titer of SJNNV in the PI-BF-2 cell was $4.8 \log \mathrm{TCID}_{50} \mathrm{ml}^{-1}$, indicating that SJNNV amplification in PI-BF-2 cells was more than 50 times higher than in BF-2 cells. The same was observed in the BF-2 and PI-BF2 cells after TrX-RGNNV inoculation, i.e. the maximum infectivity titer of TrX-RGNNV in PI-BF-2 cells was $5.05 \log \mathrm{TCID}_{50} \mathrm{ml}^{-1}$, which was 42 times higher than that in BF-2 cells (3.43 log TCID $50 \mathrm{ml}^{-1}$ ). Notably, BF-2 and PI-BF-2 cells never showed CPE after TrX-SJNNV or TrX-RGNNV inoculation, although both BF-2 and PI-BF-2 cells amplified each inoculated virus. It was thus demonstrated that BF-2 cells were permissive to fish nodaviruses, but the

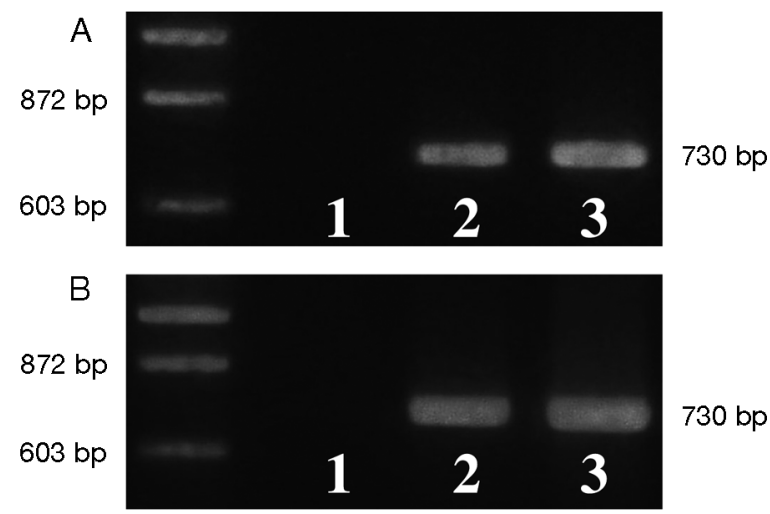

Fig. 4. Amplified products from extracted nucleic acids of BF2 (Lane 1), PI-BF-2 (Lane 2) and SSN-1 (Lane 3) cell lines by (A) RT-PCR and (B) PCR with the primers targeting the snakehead retrovirus (SnRV) pol gene. Molecular markers: $\phi$ X174 DNA-HaeIII digest 


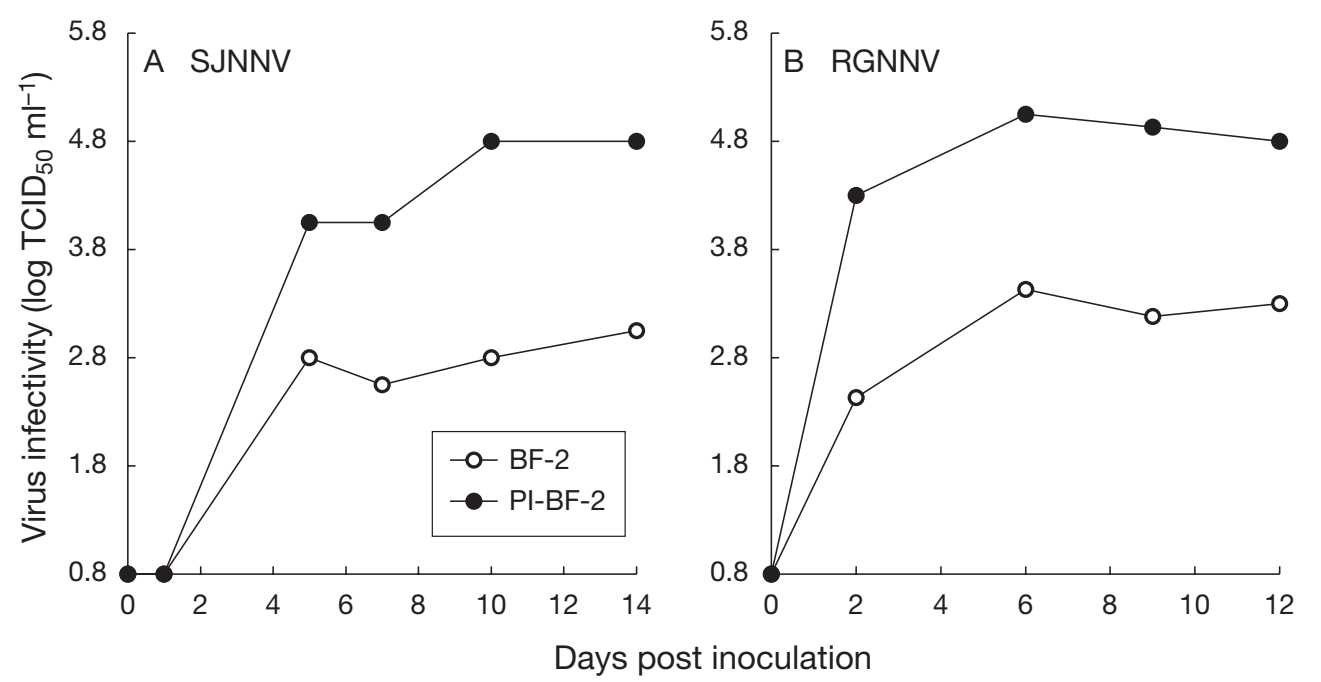

Fig. 5. Production of (A) striped jack nervous necrosis virus (SJNNV) and (B) red spotted grouper nervous necrosis virus (RGNNV) by PI-BF-2 and BF-2 cells. Snakehead retrovirus (SnRV)-free SJNNV by Triton X-100 treatment was inoculated onto each cell line for monitoring the change of SJNNV infectivity titer in cultured fluid

permissiveness of BF-2 cells for fish nodaviruses is strongly enhanced by persistent infection with SnRV.

\section{DISCUSSION}

Recently it was reported that BF-2 cells were permissive to a fish nodavirus although they displayed no CPE (Delsert et al. 1997). This was confirmed by the present data. Interestingly, BF-2 cells seem to be persistently infected with fish nodaviruses because the SJNNV- or RGNNV-inoculated BF-2 cells continued to yield each virus after several subcultures (data not shown). Chi et al. (2005) established a novel cell line (BB) from brain tissue of a barramundi Lates calcarifer surviving VNN, and the BB cell line was also persistently infected with fish nodavirus.

Iwamoto et al. (2000) attempted to clone an SnRVfree cell line from SSN-1 cells but were unsuccessful, demonstrating the difficulty of obtaining SnRV-free clones from SSN-1 cells. Furthermore, it could be postulated that successful production of fish nodavirus in the SSN-1 cell line is due to SnRV induction of the receptor for fish nodavirus (Munday \& Nakai 1997, Iwamoto et al. 2000). However, Lee et al. (2002) induced a persistently SnRV-infected GF-1 cell line (SGF-1); and found that no difference was observed in the productivity of fish nodaviral RNA and protein between GF-1 and SGF-1 cells. Thus, Lee et al. (2002) concluded that the existence of SnRV did not influence the production of fish nodavirus. However, the present data are in contrast to those previous studies, because persistent infection with SnRV enhanced the production of fish nodavirus by more than 40 times (Fig. 5). There are 2 major differences between the present study and previous studies. First, the BF-2 cell line is permissive but not cytolytic with fish nodavirus infection. Nodavirus propagation during a cytolytic infection, such as in the GF-1 and SGF-1 cell lines, may be near maximum, and therefore cytolytic infections may be unsuitable to study the influence of persistent SnRV infection on nodavirus propagation. Viral propagation during a non-cytolytic infection, such as in the BF-2 and PI-BF-2 cell lines, may be milder than that of a cytolytic infection, and thus the non-cytolytic infection system could make it possible to detect the influence of SnRV on fish nodavirus. Second, TrX treatment of fish nodaviruses was used to inactivate SnRV. Nodavirus cultured with SSN-1 cells are always contaminated with SnRV spontaneously produced by SSN-1 cells, and hence, preparation of SnRV-free nodaviruses is one of the most important points in the present investigation into the influence of SnRV on fish nodavirus propagation. Thus, it was possible to propagate fish nodaviruses in BF-2 cells without SnRV, and moreover, the productivity of fish nodaviruses by BF-2 cells was clearly enhanced by persistent infection of SnRV. Unfortunately, it was not clear whether the propagation of fish nodaviruses was directly or indirectly enhanced by persistent infection of SnRV, because there is no technique currently available to demonstrate the presence of SnRV in the same individual cells as those infected with SJNNV.

Fish nodavirus has no DNA stage in its life cycle; however, homologous DNA to nodavirus genomic RNA was detected in nodavirus-infected SGF-1 cells (Lee et al. 2002) and from Japanese flounder Paralichthys olivaceus and barfin flounder Verasper moseri clinically and subclinically infected with fish nodaviruses (Suzuki 2006). Retroviral reverse tran- 

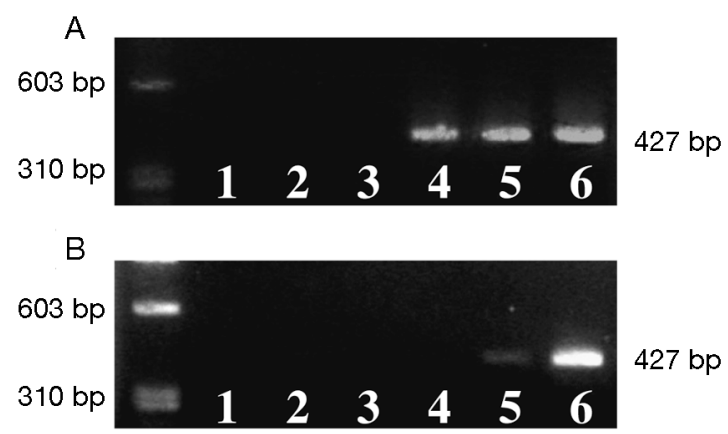

Fig. 6. Detection of homologous DNA to the striped jack nervous necrosis virus (SJNNV) genome with the primer set targeting the T4 region of SJNNV RNA2. (A) Amplified products by RT-PCR from RNAs extracted from the culture fluid of SJNNV-infected cell lines. (B) Amplified products by PCR from extracted nucleic acids of SJNNV-infected cell lines. Molecular markers: $\phi X 174$ DNA-HaeIII digest. Lane 1: BF-2 cells, Lane 2: PI-BF-2 cells, Lane 3: SSN-1 cells, Lane 4: SJNNV-infected BF-2 cells, Lane 5: SJNNV-infected PI-BF-2 cells, Lane 6: SJNNV-infected SSN-1 cells

scriptase could react with the nodaviral genome RNA to create cDNA (Lee et al. 2002, Suzuki 2006). To confirm the existence of fish nodaviral cDNA, TrX-SJNNV was inoculated to BF-2, PI-BF-2 and SSN-1 cells for PCR detection with the F2-R3 primers set (Fig. 6). No CPE was observed in these cell lines, except the SJNNV-inoculated SSN-1. The RT-PCR products with 420 bases were amplified from SJNNV-inoculated BF2, PI-BF-2 and SSN-1 cells, although no amplified product was observed from mock-infected BF-2, PIBF-2 and SSN-1 cell lines. In the PCR for detection of SJNNV cDNA, the same-sized products (420 bp) were amplified from both PI-BF-2 and SSN-1 cells inoculated with SJNNV, but no PCR product was observed from SJNNV-inoculated BF-2 cells and mock-infected cell lines (Fig. 6B). Thus, it was confirmed that SJNNV cDNA existed in the persistently SnRV-infected cell lines, PI-BF-2 and SSN-1. Lee et al. (2002) suggested that the fish nodavirus cDNA might be packed into virus particles and released into the culture fluid, but Suzuki (2006) reported the cDNA did not lead to production of fish nodavirus particles. In the present study, no cDNA was detectable from culture fluid of the SJNNV-infected PI-BF-2 and SSN-1 cells (data not shown); it could be an extremely small ratio even if the SJNNV cDNA was packed into nodaviral particles. Notably, the amount of amplified product from SJNNV-infected PI-BF-2 cells was clearly lower than that from SJNNV-infected SSN-1 cells, although no difference was observed in the production of SnRV between PI-BF-2 and SSN-1 cell lines (Fig. 4). In our future work we are interested in the quantitative relationship between the fish nodavirus cDNA and the production of fish nodaviral particles in these cell lines.
It is possible that VNN is caused by only fish nodavirus infection; however, the present study demonstrated that propagation of fish nodavirus was enhanced by SnRV infection in vitro. Moreover, fish nodavirus DNA, possibly induced by retroviral-like reverse transcriptase, was also detectable in vivo (Suzuki 2006). Thus, further studies into the influence of retrovirus on the production of fish nodaviruses in VNN-affected fishes would seem worthwhile.

Acknowledgements. This study was partially supported by a Grant-in-Aid from the Ministry of Education, Culture, Sports, Science and Technology of Japan.

\section{LITERATURE CITED}

Bandín I, Olveira JG, Borrego JJ, Dopazo CP, Barja JL (2006) Susceptibility of the fish cell line SAF-1 to betanodavirus. J Fish Dis 29:633-636

Breuil G, Bonami JR, Pepin JF, Pichot Y (1991) Viral infection (picorna-like virus) associated with mass mortalities in hatchery-reared sea-bass (Dicentrarchus labrax) larvae and juveniles. Aquaculture 97:109-116

Chew-Lim M, Chong SY, Yoshimizu M (1998) A nodavirus isolated from grouper (Epinephelus tauvina) and seabass (Lates calcarifer). Fish Pathol 33:447-448

Chi SC, Hu WW, Lo BJ (1999) Establishment and characterization of a continuous cell line (GF-1) derived from grouper, Epinephelus coioides (Hamilton): a cell line susceptible to grouper nervous necrosis virus (GNNV). J Fish Dis 22:173-182

Chi SC, Wu YC, Cheng TM (2005) Persistent infection of betanodavirus in a novel cell line derived from the brain tissue of barramundi Lates calcarifer. Dis Aquat Org 65: 91-98

Comps M, Pepin JF, Bonami JR (1994) Purification and characterization of two fish encephalitis viruses (FEV) infecting Lates calcarifer and Dicentrarchus labrax. Aquaculture 123:1-10

Delsert C, Morin N, Comps M (1997) Fish nodavirus lytic cycle and semipermissive expression in mammalian and fish cell cultures. J Virol 71:5673-5677

Frerichs GN, Morgan D, Hart D, Skerrow C, Roberts RJ, Onions DE (1991) Spontaneously productive C-type retrovirus infection of fish cell lines. J Gen Virol 72:2537-2539

Frerichs GN, Rodger HD, Peric Z (1996) Cell culture isolation of piscine neuropathy nodavirus from juvenile sea bass, Dicentrarchus labrax. J Gen Virol 77:2067-2071

Grotmol S, Totland GK, Kvellestad A, Fjell K, Olsen AB (1995) Mass mortality of larval and juvenile hatchery-reared halibut (Hippoglossus hippoglossus L.) associated with the presence of virus-like particles in the central nervous system and retina. Bull Eur Assoc Fish Pathol 15:176-180

Hart D, Frerichs GN, Rambaut A, Onions DE (1996) Complete nucleotide sequence and transcriptional analysis of the snakehead fish retrovirus. J Virol 70:3606-3616

Iwamoto T, Mori K, Arimoto M, Nakai T (1999) High permissivity of the fish cell line SSN-1 for piscine nodaviruses. Dis Aquat Org 39:37-47

Iwamoto T, Nakai T, Mori K, Arimoto M, Furusawa I (2000) Cloning of the fish cell line SSN-1 for piscine nodaviruses. Dis Aquat Org 43:81-89

Iwamoto T, Mise K, Mori K, Arimoto M, Nakai T, Okuno T (2001) Establishment of an infectious RNA transcription 
system for striped jack nervous necrosis virus, the type species of the betanodaviruses. J Gen Virol 82:2653-2662

Johansen R, Sommerset I, Tørud B, Korsnes K and others (2004) Characterization of nodavirus and viral encephalopathy and retinopathy in farmed turbot, Scophthalmus maximus (L.). J Fish Dis 27:591-601

Lai YS, Murali S, Chiu HC, Ju HY and others (2001) Propagation of yellow grouper nervous necrosis virus (YGNNV) in a new nodavirus-susceptible cell line from yellow grouper, Epinephelus awoara (Temminck \& Schlegel), brain tissue. J Fish Dis 24:299-309

Lee KW, Chi SC, Cheng TM (2002) Interference of life cycle of fish nodavirus with fish retrovirus. J Gen Virol 83: 2469-2474

Mori K, Nakai T, Nagahara M, Muroga K, Mekuchi T, Kanno $T$ (1991) A viral disease in hatchery-reared larvae and juveniles of redspotted grouper. Fish Pathol 26:209-210

Mori K, Nakai T, Muroga K, Arimoto M, Mushiake K, Furusawa I (1992) Properties of a new virus belonging to Nodaviridae found in larval striped jack (Pseudocaranx dentex) with nervous necrosis. Virology 187:368-371

Munday BL, Nakai T (1997) Special topic review: nodaviruses as pathogens in larval and juvenile marine finfish. World J Microbiol Biotechnol 13:375-381

> Munday BL, Langdon JS, Hyatt A, Humphrey JD (1992) Mass mortality associated with a viral-induced vacuolating encephalopathy and retinopathy of larval and juvenile barramundi, Lates calcarifer Bloch. Aquaculture 103: $197-211$

Munday BL, Kwang J, Moody N (2002) Betanodavirus infections of teleost fish: a review. J Fish Dis 25:127-142

Muroga K (2001) Viral and bacterial diseases of marine fish and shellfish in Japanese hatcheries. Aquaculture 202: 23-44

Muroga K, Furusawa T, Furusawa I (1998) A review: viral nervous necrosis in striped jack, Pseudocaranx dentex. Suisanzoshoko 46:473-480 (in Japanese with English Abstract)

Editorial responsibility: Mark Crane,

Geelong, Victoria, Australia
Nagai T, Nishizawa T (1999) Sequence of the non-structural protein gene encoded by RNA1 of striped jack nervous necrosis virus. J Gen Virol 80:3019-3022

Nguyen HD, Mekuchi T, Imura K, Nakai T, Nishizawa T, Muroga K (1994) Occurrence of viral nervous necrosis (VNN) in hatchery-reared juvenile Japanese flounder Paralichthys olivaceus. Fish Sci 60:551-554

Nishizawa T, Mori K, Nakai T, Furusawa I, Muroga K (1994) Polymerase chain reaction (PCR) amplification of RNA of striped jack nervous necrosis virus (SJNNV). Dis Aquat Org 18:103-107

Nishizawa T, Mori K, Furuhashi M, Nakai T, Furusawa I, Muroga K (1995) Comparison of the coat protein genes of five fish nodaviruses, the causative agents of viral nervous necrosis in marine fish. J Gen Virol 76:1563-1569

Nishizawa T, Furuhashi M, Nagai T, Nakai T, Muroga K (1997) Genomic classification of fish nodaviruses by molecular phylogenetic analysis of the coat protein gene. Appl Environ Microbiol 63:1633-1636

Qin QW, Wu TH, Jia TL, Hegde A, Zhang RQ (2006) Development and characterization of a new tropical marine fish cell line from grouper, Epinephelus coioides, susceptible to iridovirus and nodavirus. J Virol Methods 131:58-64

Schneemann A, Ball LA, Delserrt C, Hohnson JE, Nishizawa T (2005) Family Nodaviridae. In: Fauquet CM, Mayo MA, Maniloff J, Desselberger U, Ball LA (eds) Virus taxonomy. Eighth Report of the International Committee on Taxonomy of Viruses. Elsevier Academic Press, San Diego, CA, p 865-872

Suzuki K (2006) Detection of DNAs homologous to betanodavirus genome RNAs in barfin flounder Verasper moseri and Japanese flounder Paralichthys olivaceus. Dis Aquat Org 72:225-239

Tan C, Huang B, Chang SF, Ngoh GH, Munday B, Chen SC, Kwang J (2001) Determination of the complete nucleotide sequence of RNA1 and RNA2 from greasy grouper (Epinephelus tauvina) nervous necrosis virus, Singapore strain. J Gen Virol 82:647-653

Submitted: August 6, 2007; Accepted: November 12, 2007

Proofs received from author(s): January 21, 2008 